\title{
Effect of Pruning Intensity and Potash Spray on Biochemical Composition of Peach
}

\author{
Lochan Kaushik $^{1 *}$, Devi Singh ${ }^{1}$, Ritu Mittal', AshishGupta ${ }^{1}$, \\ Gaurav Kant ${ }^{1}$, Shashank Singh ${ }^{1}$ and Prashant Kaushik ${ }^{3}$ \\ ${ }^{1}$ Department of Horticulture, Chaudhary Charan Singh Haryana Agricultural University, \\ Hisar, Haryana, India \\ ${ }^{2}$ Department of Chemistry, National Institute of Technology, Kurukshetra, Haryana, India \\ ${ }^{3}$ Nagano University, 1088 Komaki, Ueda, Nagano, Japan \\ *Corresponding author
}

\section{A B S T R A C T}

Keywords

Pruning, Potash spray, Peach

\section{Article Info}

Accepted:

17 October 2020

Available Online:

10 November 2020
Present study was carried to understand a relation between pruning intensity in addition to potash spray on the biochemical characteristics of the peach fruits. We used eight years old trees of peach cultivar Shan-e-Punjab in Randomized Block Design with 3replications at CCS Haryana Agricultural Faculty, Research Farm at Kaul, Haryana, India. We considered 3 pruning intensities and $3 \mathrm{pH}$ levels of foliar potassium spray. Severe pruning, i.e., $60 \%$ pruning intensity was determined significantly more effective concerning biochemical parameters. Whereas, total soluble solids (TSS), ascorbic acid, as well as sugars have been found greater with $1.5 \%$ concentration of $\mathrm{K}_{2} \mathrm{SO}_{4}$. Also, the leaf nitrogen (N) and potassium $(\mathrm{K})$ content improved with the increasing intensity of pruning and increasing the potash application. Likewise, maximum leaf $\mathrm{N}$ and $\mathrm{K}$ were present in $60 \%$ pruning intensity and $1.5 \%$ spray of $\mathrm{K}_{2} \mathrm{SO}_{4}$, whereas, phosphorus concentration decreased with the increasing severity of pruning and foliar spraying of potash. The interaction of pruning intensity in addition to potash concentration was found non-significant in most of the parameters. Overall, this study provides content about the effect of pruning intensity in addition to potash application on biochemical framework of peach.

\section{Introduction}

Peach (Prunus persica Batsch) is among the most important temperate fruits. This fresh fruit belongs to the family Rosaceae, sub family Prunoidae. This specie originated (about 4,000-5,000 years ago) in China with subsequent dispersion in Europe from Persia, in the late centuries B.C.1, is one of the imperative specie with a global production of around 20 million tons/year. It moved further from China to west through marine route via India and mid-east and throughout the silk course via Persia (Janick, 2003). Nevertheless, several wild species of peaches exist from east to west part of Himalayas, which are used as a rootstock for peaches and nectarines. The North Indian region of Punjab 
and Haryana is not considered suitable for temperate fruits, but a distinctive group of cultivars which require fewer chilling hours for bud emergence and maturation, are considered suitable for North India (Verma et al., 2010). Presently, Sharbati, Saharanpur Prabhat, Florada Prince, Shan-e-Punjab, and Early Grande are chosen cultivars in this spot (Tiwari, 2004).

Peach are an essential source of vitamin C and vitamin A along with several mineral elements. Shan-e-Punjab is a highly popular commercial peach cultivar of central and submountainous zone of Punjab, it is likewise getting well-known status in north eastern areas of Haryana. It generally ripens on initial fortnight of May and consequently fetches remunerative amount for peach growers (Mahajan and Dhillon, 2002). The color of fresh fruit is yellow with an excellent taste and yellow flesh. Along with their table use, this cultivar has also been found perfect for canning purpose (Bal, 2006).

In peach massive bearing leads to the development of undersized fruits with poor quality of produce. Pruning, the judicious removal of any vegetative part, is a significant culture operation to produce ideal sized fruits, having excellent quality and color fruiting trees (Ahmad et al., 2006). Pruning influences berry's external and inner quality characteristics including color advancement, general soluble solid/acidity balance and many more (Demirtas et al., 2010). In peach the appropriate pruning is substantively important in regulating the tree vigour, fruit quality and productivity potential. Consequently, a judicious pruning is of high significance in regulating the shoot growth as well as fruit yield based on prevailing agroclimatic condition (Thakur and Rana2012).Potassium plays a regulatory component in many natural and biochemical processes of fruit plants like photosynthesis, nucleic acid metabolism, proteins along with carbs biosynthesis, which will enhance leaf mineral content (Krauss and Jiyun, 2000) and fresh fruit yield (Alva et al., 2006). Foliar spraying of $\mathrm{K}$ in peach is well known to rectify the inadequacies of nourishment, since the accessibility of nourishment through foliar system is well to do and agile on the plants (Babu and Yadav, 2005).

Potassium is essential and it's recognized to have dynamic effect on fruit's biochemical properties that is by influencing solids content, soluble vitamin, colour, and size (Volker and Kirkby, 2010). Since potassium may be mobilized to the current foliage, these symptoms show up in the beginning over the earlier leaves towards the basis of the vegetable (Corbino et al., 2013). The competition between making fresh fruits as well as vegetative organs for photo assimilates can easily restrict root growth activity and $\mathrm{K}$ uptake (Lester et al., 2010). Hence, keeping in perspective the advantages of pruning as well as potassium program, the current test was created to learn the results of pruning and foliar application of potash on quality of peach cv. Shan-e-Punjab.

\section{Materials and Methods}

\section{Experimental setup and material}

The present investigation was carried out on peach trees in experimental orchard, college of agriculture, Kaul, CCS Haryana Agricultural University, Hisar. The peach trees were belonging to variety Shan-ePunjab. Treatments

Foliar spray of Potassium sulphate $\left(2^{\text {nd }}\right.$ fortnight of March)

0.5 per cent spray of Potassium sulphate 1 per cent spray of Potassium sulphate 1.5 per cent spray of Potassium sulphate Control (water spray) 


\section{Fruit composition analysis}

$5 \mathrm{~g}$ of fresh fruit was taken as well as macerated using pestle and mortar with the inclusion of $10 \mathrm{ml}$ of distilled water and transferred to a test tube. The pestle and mortar were cleaned completely with five $\mathrm{ml}$ sterilized water as well as once more poured into the test tube. The tubes were coated with aluminium foil and after that maintained for 30 minutes in boiling water foot bath. The content was filtered, and very same procedure was followed three times as well as comprehensive chemical was pooled in volumetric flask along with the previous volume was made with adequate dilution. Take $25 \mathrm{ml}$ of diluted sugar extract in flask and $4 \mathrm{ml}$ concentrated $\mathrm{HCl}$ was added as well as maintained for 15 minutes in hot water bath at $68^{\circ} \mathrm{C}$ heat. Acidity was counteracted with anhydrous sodium carbonate till the effervescence ceased. Then, the quantity was produced to $50 \mathrm{ml}$ and sugar was calculated as described in reducing sugars.

The tubes were coated with aluminum foil and after that maintained for 15 minutes in boiling water foot bath. After cooling under water tap, $5 \mathrm{ml}$ of potassium iodide solution accompanied by three $\mathrm{ml}$ of acetic acid solution was added in each test tube. The endpoint was the disappearance of blue color and the appearance of milky white color. A blank was also run concurrently.

The result was estimated by utilizing the following method and expressed in percentage. The quantity of non-reducing sugars was estimated as distinction between total sugars and reducing sugars. The ascorbic acid was estimated with the help of procedure as given in AOAC (1990).

\section{Leaf NPK content (Leaf sampling mid-May to July)}

Samples were collected from center of every shoot from current season's growth in the month of October after fruit crop. Right after collection, leaves sample were brought to lab and washed with running tap water accompanied by 0.1 percent $\mathrm{HCl}$ along with 2 washings through distilled water. The washed foliage samples surface dried out and potential oven dried at $65^{\circ} \mathrm{C}$ for 48 hours. The dried samples were grinded into fine powder. For the determination of $\mathrm{N}, \mathrm{K}$ and $\mathrm{P}$, a ground leaf sample of $0.5 \mathrm{~g}$ was taken in a conical flask as well as ten $\mathrm{ml}$ of diacid combination $\left(\mathrm{H}_{2} \mathrm{SO}_{4}: \mathrm{HClO}_{4}\right.$ in 9:1 ratio) was added and digested on a warm plate adopting the strategy mentioned by Jackson (1967) for calculations of $\mathrm{N}, \mathrm{K}$ and $\mathrm{P}$. The nitrogen content in plant leaves was determined by utilizing the strategy mentioned by Jackson (1973). An aliquot of $0.2 \mathrm{ml}$ was drawn in a $50 \mathrm{ml}$ volumetric flask along with $1 \mathrm{ml}$ of sodium silicate and additional $0.5 \mathrm{ml}$ of percent $\mathrm{NaOH}$ was provided. Neck washing was carried out after inclusion of the contents and every reagent were combined thoroughly. To the $2 \mathrm{ml}$ of Nessler's reagent was added drop by drop and shaking simultaneously. The last volume was made to $50 \mathrm{ml}$. The solution was permitted to stand for 30 minutes at room temperature.

Spectronic 20 Spectrophotometer was used for the optical density measurement at 420 $\mathrm{nm}$. A regular curve was prepared from graded amounts of ammonium chloride. The nitrogen content was calculated and conveyed as percent on dry weight regime. The foliage phosphorus content was determined by utilizing Vanadomolybdo phosphoric acid yellow colored method as mentioned by Jackson (1973) as well as conveyed in per cent. Flame Photometer was used for the potassium content estimation. The contents were estimated and expressed in percent on dry weight basis. Statistical analysis of data collected during the study was done by applying the technique of analysis of variance (Rai and Grover, 2006). All the statistical 
analysis was carried out by using OPSTAT statistical software (Sheoran, 2004).

\section{Results and Discussion}

Content gathered on total soluble solids (TSS) of fruits as affected by pruning levels and spray of potash were portrayed in Table 1 and revealed that the optimum TSS of fresh fruits $\left(11.20^{\circ} \mathrm{B}\right)$ was recorded in fresh fruits taken from vegetation subjected to60 percent pruning intensity, which was followed by fruits harvested from plants receiving 40 percent $\left(10.67^{\circ} \mathrm{B}\right)$ and 20 percent $\left(10.01^{\circ} \mathrm{B}\right)$ pruning intensity as well as the minimum TSS was registered in fruits taken from unpruned trees $\left(9.01^{\circ} \mathrm{B}\right)$.

Different concentration of potash spray also significantly affected the TSS of fresh fruits. The plants sprayed with 1.5 percent K2S04 recorded the optimum TSS of fresh fruits $\left(10.68{ }^{\circ} \mathrm{B}\right)$, which was followed by fresh fruits taken from plant life with spray of 1.0 percent $\mathrm{K} 2 \mathrm{SO} 4\left(10.38{ }^{\circ} \mathrm{B}\right)$ and 0.5 percent $\mathrm{K} 2 \mathrm{SO} 4$ $\left(10.09{ }^{\circ} \mathrm{B}\right)$, even though the minimum TSS was recorded in fruits harvested from plants with spraying of water $\left(9.73^{\circ} \mathrm{B}\right)$. The interaction impact of pruning and potash spray was found non-significant in regard of TSS of fresh fruits.

The perusal of facts shown in Table 2 reveals that acidity of fruit was substantially affected by pruning levels and spray of potash in peach. The least acidity of fresh fruits $(0.44$ $\%$ ) was recorded in fresh fruits taken from vegetation subjected to 60 percent pruning intensity, which was followed by fruits harvested from plants receiving 40 percent $(0.47 \%)$ and 20 percent $(0.49 \%)$ pruning intensity as well as the acidity was found optimum in fruits taken from unpruned trees $(0.52 \%)$.

Spray of potash also significantly affected the acidity of fresh fruits. The least acidity of fresh fruits $(0.46 \%)$ was recorded in fresh fruits taken from plant life with spray of 1.5 per cent $\mathrm{K}_{2} \mathrm{SO}_{4}$, which was statistically at par with fresh fruits taken from plants with spray of 1.0 per cent $\mathrm{K}_{2} \mathrm{SO}_{4}(0.47 \%)$ and also followed by 0.5 per cent $\mathrm{K}_{2} \mathrm{SO}_{4}(0.48 \%)$, whereas the highest acidity was noticed in fruits harvested from plants with waterspray $(0.5 \%)$. There was non-significant effect on acidity of fruit with respect to interaction of pruning and potash spray. Data regarding TSS to acid ratio continues to be narrated in Table 3. The optimum TSS: Acid ratio of fruits (25.24) was recorded in fruits taken from vegetation subjected to 60 percent pruning intensity, which was followed by fruits harvested from plants receiving 40 percent (23.06) and 20 percent (20.50) pruning intensity and also the minimum in fruits taken from unpruned trees (17.32).

Different pruning amounts influenced the pulp TSS: Acid ratio considerably. Nevertheless, the optimum TSS: Acid ratio (23.35) was captured with 1.5 per cent potash spray followed by plants with spray of 1.0 per cent $\mathrm{K}_{2} \mathrm{SO}_{4}$ (22.10) and 0.5 per cent $\mathrm{K} 2 \mathrm{SO} 4$ (21.08), while the minimum TSS: Acid ratio was recorded in fruits harvested from plants with waterspray (19.60).

The interaction impact of pruning and potash spray was found considerable in regard of TSS: Acid ratio. The optimum TSS: Acid ratio of fruits were noticed together of 60 percent pruning intensity and spray of 1.5 per cent $\mathrm{K}_{2} \mathrm{SO}_{4}$ (28.56) that had been considerably superior over the other treatments together and least in combination of plants with no spray and pruning of water (16.40).

The results on total sugar content of fruits arranged in Table 4 reveals that the maximum total sugars of fresh fruits $(7.27 \%)$ was recorded in fruits taken from vegetation getting 60 percent pruning intensity, which 
was followed by fruits harvested from plants receiving 40 percent $(6.69 \%)$ and 20 per cent $(6.12 \%)$ pruning intensity as well as the minimum total sugars was registered in fruits taken from unpruned trees $(5.57 \%)$.

Impact of various awareness of potash spray had also been substantially affected the overall sugars of fruits. The maximum complete sugars of fresh fruits $(6.81 \%)$ was recorded in fresh fruits taken from plant life with spray of 1.5 per cent $\mathrm{K}_{2} \mathrm{SO}_{4}$, which was followed by fresh fruits taken from plants with spray of 1.0 per cent $\mathrm{K}_{2} \mathrm{SO}_{4}(6.53 \%)$ and 0.5 per cent $\mathrm{K}_{2} \mathrm{SO}_{4}(6.33 \%)$, while the minimum complete sugar was recorded in fruits harvested from plants with waterspray $(5.97 \%)$.

The interaction impact of pruning and potash spray was found considerable in respect of complete sugar. The highest total sugar of fruits was noticed together of 60 per cent pruning intensity and also spray with 1.5 per cent K2SO4 (7.96 \%), that had been considerably superior over all of the remedies as well as the minimum total sugar was obtained together of plant life with no spray and pruning of water $(5.33 \%)$.

The Data provided in Table five reveals that pruning intensity greatly affected the decreasing sugars of peach fruits. The highest lowering sugars of fresh fruits $(5.30 \%)$ was recorded in fresh fruits taken from vegetation getting 60 per cent pruning intensity, which was followed by fruits harvested from plants receiving 40 per cent $(4.86 \%)$ and 20 per cent $(4.38 \%)$ pruning intensity and also the minimum in fruits taken from unpruned trees (4.01\%).

Various spray of potash also substantially affected the lowering sugar of fruits. The highest decreasing sugars of fresh fruits (4.94 $\%$ ) was recorded in fruits of vegetation spray with 1.5 per cent $\mathrm{K}_{2} \mathrm{SO}_{4}$, which was followed by fresh fruits taken from plant life with spray of 1.0 per cent $\mathrm{K} 2 \mathrm{SO} 4(4.73 \%)$ and 0.5 per cent $\mathrm{K}_{2} \mathrm{SO}_{4}(4.57 \%)$, even though the bare minimum minimizing sugars was recorded in fruits harvested from plants with waterspray (4.31\%).

The interaction impact of pruning amounts and spray of potash on decreasing sugar of fruit was discovered considerable. The optimum decreasing sugars $(5.82 \%)$ was recorded in fresh fruits taken from vegetation getting 60 per cent pruning intensity along with spray of 1.5 per cent $\mathrm{K} 2 \mathrm{SO} 4$, which was significantly superior to various other treatments, even though the bare minimum minimizing sugar $(3.84 \%)$ was recorded in fruits harvested from unpruned trees spraying with water. The content gathered on non-reducing sugar provided in Table six shows that there is considerable impact of pruning levels and also spray of potash on non-reducing sugar of fruits. The maximum non reducing sugars of fresh fruits $(1.97 \%)$ was recorded in fruits harvested from plants receiving 60 per cent pruning intensity, which was followed by fresh fruits taken from vegetation getting 40 per cent $(1.82 \%)$ and 20 per cent $(1.74 \%)$ pruning intensity and also the least percentage of nonreducing sugar was observed from fresh fruits taken from unpruned trees $(1.55 \%)$. The spray of potash even affected the non-reducing sugar of fruits greatly. The maximum non reducing sugars of fresh fruits $(1.87 \%)$ was recorded in fresh fruits taken from plant life with spray of 1.5 per cent $\mathrm{K} 2 \mathrm{SO} 4$, which was statistically at par with foliar spray of 1.0 per cent K2SO4 $(1.80 \%)$ and 0.5 per cent K2SO4 (1.76\%), even though the minimum non reducing sugar was recorded in fruits harvested from plants with waterspray $(1.66 \%)$.

The interaction impact of pruning levels and the spray of potash on non-reducing sugar of fruit was discovered to be non-significant. The perusal of facts shown in Table 7 discloses that ascorbic acid of fresh fruits 
substantially affected by various pruning levels and spray of potash in peach. The highest ascorbic acid of fresh fruits $(8.83 \%)$ was recorded in fresh fruits taken from vegetation getting 60 per cent pruning intensity, which was followed by fresh fruits taken from vegetation getting 40 per cent $(8.40 \%)$ and 20 per cent pruning intensity $(8.00 \%)$ as well as the unpruned tree registered the least ascorbic acid $(7.78 \%)$.

Spray of potash also substantially influenced ascorbic acid of fresh fruits. The highest ascorbic acid of fresh fruits $(8.40 \%)$ was recorded in fruits taken from plant life with spray of 1.5 per cent $\mathrm{K} 2 \mathrm{SO} 4$, which was followed by fruits harvested from plants with spray of 1.0 per cent $\mathrm{K}_{2} \mathrm{SO}_{4}(8.36 \%)$ and 0.5 per cent $\mathrm{K}_{2} \mathrm{SO}_{4}(8.23 \%)$, while the minimum ascorbic acid of fruits was recorded in fruits harvested from plants with waterspray (8.03 $\%)$.

The interaction impact of pruning quantities and potash spray had no substantial impact on ascorbic acid of fresh fruits.

\section{Leaf NPK content (Leaf sampling mid May to July)}

It's apparent from the Table 9 that nitrogen content of leaves was substantially impacted by various pruning intensity. The highest nitrogen content of foliage $(2.29 \%)$ was recorded in foliage taken from vegetation getting 60 percent pruning intensity, which was followed by foliage taken from vegetation getting 40 per cent $(2.25 \%)$ and 20 per cent $(2.20 \%)$ pruning intensity as well as the minimum in leaves taken from unpruned trees $(2.16 \%)$. Spray of potash also substantially influenced the nitrogen content of leaves. The highest nitrogen content of foliage $(2.25 \%)$ was recorded in foliage taken from plant life with 1.5 per cent potash spray, that had been statistically at par with actually leaves taken from plants with spray of 1.0 per cent $\mathrm{K}_{2} \mathrm{SO}_{4}(2.23 \%)$ and also followed by spray of 0.5 per cent $\mathrm{K}_{2} \mathrm{SO}_{4}(2.21 \%)$, while the minimum nitrogen content of leaves was recorded in leaves taken from plants with spray of 1.5 per cent $\mathrm{K}_{2} \mathrm{SO}_{4}(2.20 \%)$. Generally, there was no interaction impact of pruning quantities as well as chemical substances spray on nitrogen content of leaves. The content provided in Table 8 reveals that phosphorus content of leaves substantially affected by pruning levels and spray of potash. The highest phosphorus content of foliage $(0.18 \%)$ was recorded in foliage taken from vegetation receiving no pruning, which was statistically at par with leaves taken from vegetation receiving 20 per cent pruning $(0.17 \%)$ and 40 per cent $(0.18$ $\%)$ pruning intensity and the minimum phosphorus content $(0.18 \%)$ in leaves taken from plants getting 60 percent pruning.

Spray of potash also substantially influenced the phosphorus content of leaves. The highest phosphorus content of foliage $(0.18 \%)$ was recorded in foliage taken from plants with water spray, that had been statistically at par with phosphorus content of foliage leaves taken from plant life with spray of 0.5 per cent $\mathrm{K}_{2} \mathrm{SO}_{4}(0.17 \%)$ and 1.0 per cent $\mathrm{K}_{2} \mathrm{SO}_{4}$ $(0.17 \%)$, while the minimum phosphorus content of leaves $(0.16 \%)$ was recorded in leaves taken from plants with spray of 1.5 per cent $\mathrm{K}_{2} \mathrm{SO}_{4}$.

The interaction impact of pruning quantities and also potash spray didn't alter the phosphorus content of leaves greatly. The content provided in Table 10 reveals that potassium content of leaves was substantially affected by pruning levels and spray of potash in peach. The highest potassium content of foliage $(0.80 \%)$ was recorded in foliage taken from vegetation getting 60 percent pruning intensity, which was statistically at par with leaves taken from vegetation getting 40 percent $(0.74 \%)$ and also followed by 20 per cent $(0.70 \%)$ pruning intensity and the 
minimum potassium content in leaves was noticed in unpruned trees $(0.66 \%)$.

Spray of potash also substantially influenced the potassium content of leaves. The highest potassium content of foliage $(0.83 \%)$ was recorded in foliage taken from plant life with spray of 1.5 per cent $\mathrm{K}_{2} \mathrm{SO}_{4}$, which was followed by application of 1.0 percent $\mathrm{K}_{2} \mathrm{SO}_{4}$
$(0.79 \%)$ and 0.5 per cent $\mathrm{K}_{2} \mathrm{SO}_{4}(0.73 \%)$, while the minimum potassium content of leaves was recorded in leaves taken from plants with waterspray $(0.57 \%)$. The interaction between of pruning amounts and potash spray was not able in exerting any considerable impact on potassium content of leaves.

Table.1 Effect of pruning intensity and foliar application of potash on TSS $\left({ }^{\circ} \mathrm{B}\right)$

\begin{tabular}{|c|c|c|c|c|c|}
\hline \multirow{2}{*}{ Pruning levels } & \multicolumn{5}{|c|}{ Potash concentration (\%) } \\
\cline { 2 - 6 } & Water spray & $\mathbf{0 . 5}$ & $\mathbf{1}$ & $\mathbf{1 . 5}$ & Mean \\
\hline Control (no pruning) & 8.83 & 8.87 & 9.13 & 9.20 & 9.01 \\
\hline Light pruning (20\%) & 9.57 & 10.00 & 10.17 & 10.30 & 10.01 \\
\hline Medium pruning (40\%) & 10.07 & 10.60 & 10.80 & 11.20 & 10.67 \\
\hline Heavy pruning (60\%) & 10.43 & 10.90 & 11.43 & 12.03 & 11.20 \\
\hline Mean & 9.73 & 10.09 & 10.38 & 10.68 & \\
\hline CD at 5\% & $\mathrm{P}=0.24$ & $\mathrm{~K}=0.24$ & $\mathrm{P} \times \mathrm{K}=\mathrm{NS}$ \\
\hline
\end{tabular}

Table.2 Effect of pruning intensity and foliar application of potash on Acidity (\%)

\begin{tabular}{|c|c|c|c|c|c|}
\hline \multirow{2}{*}{ Pruning levels } & \multicolumn{5}{|c|}{ Potash concentration (\%) } \\
\cline { 2 - 6 } & Water spray & $\mathbf{0 . 5}$ & $\mathbf{1}$ & $\mathbf{1 . 5}$ & Mean \\
\hline Control (no pruning) & 0.54 & 0.52 & 0.52 & 0.51 & 0.52 \\
\hline Light pruning (20\%) & 0.52 & 0.49 & 0.48 & 0.47 & 0.49 \\
\hline Medium pruning (40\%) & 0.49 & 0.47 & 0.45 & 0.45 & 0.47 \\
\hline Heavy pruning (60\%) & 0.46 & 0.45 & 0.44 & 0.42 & 0.44 \\
\hline Mean & 0.50 & 0.48 & 0.47 & 0.46 & \\
\hline CD at 5\% & $\mathrm{P}=0.01$ & $\mathrm{~K}=0.01$ & $\mathrm{P} \times \mathrm{K}=\mathrm{NS}$ \\
\hline
\end{tabular}

Table.3 Effect of pruning intensity and foliar application of potash on TSS: Acid ratio

\begin{tabular}{|c|c|c|c|c|c|}
\hline & \multicolumn{5}{|c|}{ Potash concentration (\%) } \\
\hline Pruning levels & Water spray & 0.5 & 1 & 1.5 & \\
\hline Control (no pruning) & 16.40 & 17.39 & 17.48 & 18.00 & Mean \\
\hline Light pruning (20\%) & 18.65 & 20.01 & 21.30 & 22.01 & 20.50 \\
\hline Medium pruning (40\%) & 20.61 & 22.85 & 23.98 & 24.82 & 23.06 \\
\hline Heavy pruning (60\%) & 22.72 & 24.05 & 25.65 & 28.56 & 25.24 \\
\hline Mean & 19.60 & 21.08 & 22.10 & 23.35 & \\
\hline CD at 5\% & \multicolumn{2}{|c|}{$\mathrm{P}=0.58$} & $\mathrm{~K}=0.58$ & $\mathrm{P} \times \mathrm{K}=1.17$ \\
\hline
\end{tabular}


Table.4 Effect of pruning intensity and foliar application of potash on Total Sugar (\%)

\begin{tabular}{|c|c|c|c|c|c|}
\hline \multirow{2}{*}{ Pruning levels } & \multicolumn{5}{|c|}{ Potash concentration (\%) } \\
\hline & Water spray & $\mathbf{0 . 5}$ & $\mathbf{1}$ & $\mathbf{1 . 5}$ & Mean \\
\hline Control (no pruning) & 5.33 & 5.61 & 5.56 & 5.76 & 5.57 \\
\hline Light pruning (20\%) & 5.77 & 6.05 & 6.26 & 6.40 & 6.12 \\
\hline Medium pruning (40\%) & 6.17 & 6.63 & 6.81 & 7.13 & 6.69 \\
\hline Heavy pruning (60\%) & 6.63 & 7.01 & 7.48 & 7.96 & 7.27 \\
\hline Mean & 5.97 & 6.33 & 6.53 & 6.81 & \\
\hline CD at 5\% & $\mathrm{P}=0.17$ & & $\mathrm{~K}=0.17$ & $\mathrm{P} \times \mathrm{K}=0.35$ \\
\hline
\end{tabular}

Table.5 Effect of pruning intensity and foliar application of potash on Reducing Sugar (\%)

\begin{tabular}{|c|c|c|c|c|c|}
\hline \multirow{2}{*}{ Pruning levels } & \multicolumn{5}{|c|}{ Potash concentration (\%) } \\
\cline { 2 - 6 } & Water spray & $\mathbf{0 . 5}$ & $\mathbf{1}$ & $\mathbf{1 . 5}$ & Mean \\
\hline Control (no pruning) & 3.84 & 4.04 & 4.01 & 4.17 & 4.01 \\
\hline Light pruning (20\%) & 4.12 & 4.31 & 4.50 & 4.59 & 4.38 \\
\hline Medium pruning (40\%) & 4.50 & 4.81 & 4.95 & 5.19 & 4.86 \\
\hline Heavy pruning (60\%) & 4.81 & 5.11 & 5.46 & 5.82 & 5.30 \\
\hline Mean & 4.31 & 4.57 & 4.73 & 4.94 & \\
\hline CD at 5\% & $\mathrm{P}=0.11$ & & $\mathrm{~K}=0.11$ & $\mathrm{P} \times \mathrm{K}=0.22$ \\
\hline
\end{tabular}

Table.6 Effect of pruning intensity and foliar application of potash on Non-Reducing Sugar (\%)

\begin{tabular}{|c|c|c|c|c|c|}
\hline Pruning levels & \multicolumn{5}{|c|}{ Potash concentration (\%) } \\
\cline { 2 - 6 } & Water spray & $\mathbf{0 . 5}$ & $\mathbf{1}$ & $\mathbf{1 . 5}$ & Mean \\
\hline Control (no pruning) & 1.49 & 1.57 & 1.56 & 1.59 & 1.55 \\
\hline Light pruning (20\%) & 1.66 & 1.74 & 1.76 & 1.81 & 1.74 \\
\hline Medium pruning (40\%) & 1.67 & 1.82 & 1.86 & 1.94 & 1.82 \\
\hline Heavy pruning (60\%) & 1.81 & 1.90 & 2.02 & 2.14 & 1.97 \\
\hline Mean & 1.66 & 1.76 & 1.80 & 1.87 & \\
\hline CD at 5\% & $\mathrm{P}=0.12$ & $\mathrm{~K}=0.12$ & $\mathrm{P} \times \mathrm{K}=\mathrm{NS}$ \\
\hline
\end{tabular}

Table.7 Effect of pruning intensity and foliar application of potash on Ascorbic acid (mg/100 g Pulp)

\begin{tabular}{|c|c|c|c|c|c|}
\hline \multirow{2}{*}{ Pruning levels } & \multicolumn{5}{|c|}{ Potash concentration (\%) } \\
\cline { 2 - 6 } & Water spray & $\mathbf{0 . 5}$ & $\mathbf{1}$ & $\mathbf{1 . 5}$ & Mean \\
\hline Control (no pruning) & 7.67 & 7.77 & 7.80 & 7.90 & 7.78 \\
\hline Light pruning (20\%) & 7.87 & 7.97 & 8.10 & 8.07 & 8.00 \\
\hline Medium pruning (40\%) & 8.03 & 8.40 & 8.57 & 8.60 & 8.40 \\
\hline Heavy pruning (60\%) & 8.53 & 8.80 & 8.97 & 9.03 & 8.83 \\
\hline Mean & 8.03 & 8.23 & 8.36 & 8.40 & \\
\hline CD at 5\% & $\mathrm{P}=0.14$ & $\mathrm{~K}=0.14$ & $\mathrm{P} \times \mathrm{K}=\mathrm{NS}$ \\
\hline
\end{tabular}


Table.8 Effect of pruning intensity and foliar application of potash on Phosphorus content (\%) of leaves

\begin{tabular}{|c|c|c|c|c|c|}
\hline \multirow{2}{*}{ Pruning levels } & \multicolumn{5}{|c|}{ Potash concentration (\%) } \\
\cline { 2 - 6 } & Water spray & $\mathbf{0 . 5}$ & $\mathbf{1}$ & $\mathbf{1 . 5}$ & Mean \\
\hline Control (no pruning) & 0.19 & 0.18 & 0.18 & 0.17 & 0.18 \\
\hline Light pruning (20\%) & 0.18 & 0.17 & 0.17 & 0.16 & 0.17 \\
\hline Medium pruning (40\%) & 0.19 & 0.18 & 0.18 & 0.17 & 0.18 \\
\hline Heavy pruning (60\%) & 0.16 & 0.16 & 0.15 & 0.15 & 0.15 \\
\hline Mean & 0.18 & 0.17 & 0.17 & 0.16 & \\
\hline CD at 5\% & $\mathrm{P}=0.01$ & $\mathrm{~K}=0.01$ & \multicolumn{2}{c|}{$\mathrm{P} \times \mathrm{K}=\mathrm{NS}$} \\
\hline
\end{tabular}

Table.9 Effect of pruning intensity and foliar application of potash on Nitrogen content $(\%)$ of leaves

\begin{tabular}{|c|c|c|c|c|c|}
\hline \multirow{2}{*}{ Pruning levels } & \multicolumn{5}{|c|}{ Potash concentration (\%) } \\
\cline { 2 - 6 } & Water spray & $\mathbf{0 . 5}$ & $\mathbf{1}$ & $\mathbf{1 . 5}$ & Mean \\
\hline Control (no pruning) & 2.14 & 2.15 & 2.17 & 2.19 & 2.16 \\
\hline Light pruning (20\%) & 2.17 & 2.19 & 2.21 & 2.23 & 2.20 \\
\hline Medium pruning (40\%) & 2.23 & 2.24 & 2.25 & 2.26 & 2.25 \\
\hline Heavy pruning (60\%) & 2.26 & 2.28 & 2.29 & 2.31 & 2.29 \\
\hline Mean & 2.20 & 2.21 & 2.23 & 2.25 & \\
\hline CD at 5\% & $\mathrm{P}=0.03$ & $\mathrm{~K}=0.03$ & $\mathrm{P} \times \mathrm{K}=\mathrm{NS}$ \\
\hline
\end{tabular}

Table.10 Effect of pruning intensity and foliar application of potash on Potassium content (\%) of leaves

\begin{tabular}{|c|c|c|c|c|c|}
\hline \multirow{2}{*}{ Pruning levels } & \multicolumn{5}{|c|}{ Potash concentration (\%) } \\
\cline { 2 - 6 } & Water spray & $\mathbf{0 . 5}$ & $\mathbf{1}$ & $\mathbf{1 . 5}$ & Mean \\
\hline Control (no pruning) & 0.48 & 0.68 & 0.74 & 0.76 & 0.66 \\
\hline Light pruning (20\%) & 0.54 & 0.71 & 0.76 & 0.80 & 0.70 \\
\hline Medium pruning (40\%) & 0.58 & 0.73 & 0.81 & 0.86 & 0.74 \\
\hline Heavy pruning (60\%) & 0.66 & 0.79 & 0.85 & 0.91 & 0.80 \\
\hline Mean & 0.57 & 0.73 & 0.79 & 0.83 & \\
\hline CD at 5\% & $\mathrm{P}=0.08$ & $\mathrm{~K}=0.08$ & $\mathrm{P} \times \mathrm{K}=\mathrm{NS}$ \\
\hline
\end{tabular}

Increased TSS, reducing sugar, ascorbic acid, non-reducing sugar and total sugars in fresh fruits as a consequence of enhanced pruning severity could be identified on the basis of enhanced leaf to fruit ratio and consequently synthesis of carbohydrates along with the translocation and other metabolites to the fruit cells. The fruits from unpruned trees produced highest acidity. The pruning resulted in a significant decline in acidity of fruits might be owing to enhanced fruit size in addition to moisture content in fruit with enhanced pruning intensity (Mahajan and Dhilion, 2002; Thakur and Rana, 2014). Similar results were also discussed by (Kumar et al., 2010) in Flordasun peach. In July Elberta peach total soluble solids, TSS: Acid ratio,nonreducing sugars had been considerably increased in fruits of tremendously pruned trees as discussed by Pant et al., (2015).Singh et al., (2012) observed a good fruit quality with enhanced TSS content and increased 
colour with the long pruning instead of the traditional brief pruning process in peach cultivars (Hasani and Rezaei, 2007). The total soluble sugars, TSS: Acid ratio, ascorbic acid, reducing sugar, non-reducing sugar and total sugars significantly improved with the foliar spraying of potassium sulphate. The increase in total soluble solids, TSS: Acid ratio, ascorbic acid, reducing sugar, non-reducing sugar and total sugars in fresh fruits with foliar application of potash might be hooked up with responsibility of potassium in the synthesis of more carbohydrates in addition to its translocation from foliage to fruits. But acidity was found to be diminished with the potassium spray. These results are in line with past findings of Gill et al., (2012) in pear cv. Patharnakh for total soluble solids, Hamza et al., (2012) in Clementine citrus cv. Cadoux and Siddappa in Kinnow mandarin. Potassium was found to take down the acidity of the juice in Perlette (Thakur et al., 2008).

Kassem et al., (2010) observed improved fruit mass, total soluble solids, total sugars, rducing sugars as a consequence of foliar application of potassium in Costata persimmon trees. Kaur et al., (2012) discovered that application of 2.0 percent spray of potassium nitrate magnified the total soluble solids at the same time as TSS: Acid ratio. The vegetation having moderate and severe pruning had considerably highest nitrogen in addition to potassium content of foliage than unpruned trees. Higher nitrogen in severely pruned trees might be due to diminished yield per tree and less common accumulation of dried matter in leaves. Since nitrogen is mobile, its translocation to leaves could have aided the accumulation of it in peach leaves. The outcomes confirmed the findings of Kaith et al., (2011) in apple. Nevertheless, higher potassium content of foliage in severely pruned trees might be due to less buildup of dry matter and vigorous growth, which caused increased uptake of this specific component. Similar observations have been reported by Kumar and Thakur (2012) in plum. Most likely the highest phosphorus content of leaves was recorded in unpruned trees than pruned trees. This might be connected towards the antagonism between phosphate and nitrate anions at absorption sites. Nitrogen in addition to potassium was noticed to be improved by potassium foliar spraying while, phosphorus content was observed to be diminished with potassium foliar spray.

Sharma and Chauhan (2003) observed sizable interaction between pruning and fertilization on maturity, acidity, leaf $\mathrm{N}, \mathrm{Ca}$ contents and non-considerable on TSS, leaf $\mathrm{K}$ and $\mathrm{P}$ contents in peach. Bennewitz et al., (2011) additionally found that two consecutive years of extreme pruning in' Bing'/ Gisela ${ }^{\circledR 6}$ ' sweet cherry enhance leaf contents $(\mathrm{N}, \mathrm{P}$ and $\mathrm{K})$ in addition to fruit contents as when in contrast with non-pruned trees. Thakur (2012) reported that the foliar nutrient content of $\mathrm{N}$ improved with the heavy pruning treatment along with increasing quantities of nitrogen, while $\mathrm{P}, \mathrm{K}$ showed declining trends with the increasing pruning severity in addition to nitrogen levels. The effect of potash spraying on nitrogen, potassium content in peach foliage improved with potash spraying while waterspray had absolutely no influence. Nevertheless, there was an increasing potassium quantity with enhanced amounts of potassium. With expansion in quantity of foliar application of $\mathrm{K} 2 \mathrm{SO} 4$ the leaf potassium report improved. This might be due to instant absorption of potassium through leaves. These results are in agreement with the findings of Dilmaghani (2007) in apple tree, Hudina et al., (2002) in pear tree, Rashid et al., (2008) in apple tree, Papp (2000) in apple, Neilsen and Neilsen (2011) and Aroosa (2014) in grape. Eryuce et al., (2004) proved that leaf along with fruit nutrient element contents had been upgraded with improved 
potassium doses in apricot tree. Increased application of $\mathrm{K}$ caused a significant expansion of this specific element in each fresh fruits and leaves, however, not in a continuous fashion, while leaf $\mathrm{P}$ content displayed a continuous drop with increasing degree of K (Chatzitheodorou et al., (2004).

In conclusions the acidity of fresh fruits drop with the improved pruning severity along with potassium spray and it was observed minimum in fruit utilized from $60 \%$ pruning severity along with maximum in fruits harvested from controlled trees. As for as potash spraying, the optimum acidity was contained in fruits taken from trees sprayed with water spray, while minimum in fresh fruits harvested from trees with 1.5 per cent spray of K2SO4.

Quality parameters viz. TSS, TSS: Acid ratio, reducing sugar, total sugars, non-reducing sugar and ascorbic acid was noticed highest with increasing pruning levels as well as potassium spray. The maximum TSS, TSS: Acid ratio, reducing sugar, total sugars, nonreducing sugars and ascorbic acid was seen in fruits taken from 60 per cent pruning intensity along with minimum in fresh fruits harvested from trees with no pruning. Every quality parameter has been recorded optimum in 1.5 $\%$ spraying of $\mathrm{K}_{2} \mathrm{SO}_{4}$ and minimum with water spray. Interaction effect of 60 percent pruning along with foliar spray of 1.5 per cent $\mathrm{K}_{2} \mathrm{SO}_{4}$ was found finest in respect of TSS: Acid ratio, total sugars and reducing sugar. Higher pruning intensity and foliar spray of 1.5 percent $\mathrm{K}_{2} \mathrm{SO}_{4}$ was observed best to improve the $\mathrm{N}$ and $\mathrm{K}$ content of leaves, while phosphorus content was reduced with increasing concentration of potash spray along with pruning intensity. From the above results, it is concluded that 60 per cent pruning intensity was discovered significantly more effective in regard of quality parameters. Potassium sulphate 1.5 per cent spray was found very best quality characters of peach.

\section{References}

A.O.A.C. (1980). Official Methods of Analysis. Association of Analytical Chemists, 13th edn. Washington DC, USA.

Alva AK, Mattos DJ, Paramasivam S, Patil B, Dou H, Sajwan KS (2006) Potassium management for optimizing citrus production and quality. International Journal of Fruit Science, 6: 3-43.

Ahmad S, Chatha ZA, Nasir MA, Aziz A, Virk NA, Khan AR (2006) Effect of Pruning on the Yield and Quality of Kinnow Fruit. Journal of Agriculture and Social Sciences, Pp. 1813-2235.

Aroosa K (2014) Standardization of management techniques to enhance growth, yield and quality of grape (Vitis vinifera) cv. Sahebi. Ph.D. Thesis, Shere-Kashmir University of Agricultural Sciences and Technology, Kashmir, Shalimar, Srinagar.

Babu KD, Yadav DS (2005) Foliar spray of micronutrients for yield and quality improvement in Khasi mandarin (Citrus reticulata Blanco). Indian Journal of Horticulture, 62: 280-281.

Bal JS (2006) Fruit growing. Second Revised Edition. Kalyani Publishers, New Delhi.

Bangerth, F. (1999). Second discussion meeting on bitter pit in apple. Acta Horticulturae, 45: 53-52.

Bennewitz EV, Fredes C, Losak T, Martínez C, Hlusek J (2011) Effects on fruit production and quality of different dormant pruning intensities in 'Bing'/'Gisela ${ }^{\circledR} 6$ ' sweet cherries (Prunus avium) in Central Chile. International Journal of Agriculture and Natural Resources, 38: 339-344.

Chatzitheodorou IT, Sotiropoulos TE, Mouhtaridou GI, Almaliotis D (2004) Effect of nitrogen, phosphorus, potassium fertilizers and manure on growth and productivity of the peach 
cultivars 'Springtime and Redhaven'. Horticulture Science, 31: 88-92.

Corbino GB, Sanchez G, Gonzalez J, Murray RE, Gabilondo J, Valentini GH, Arroyo LE (2013) Pre and post-harvest management affects functional quality of peach (Prunus persica L.) cv. Flavorcrest. Advances in Horticultural, 27: 159-165.

DemirtasMN, Bolat I, Ercisli S, Ikinci A, Olmez HA, Sahin M, Altindag M, Celik B (2010) The effects Of Different Prunning Treatments on the Growth, Fruit Quality and Yield of 'Hacihaliloglu' Apricot. Acta Scientiarum Polonorum Horticulture 9: 183-192.

Dilmaghani MR, Malakouti MJ, Neilsen GH, Fallahi E (2005) Interactive Effects of Potassium and Calcium on $\mathrm{K} / \mathrm{Ca}$ Ratio and Its Consequences on Apple Fruit Quality in Calcareous Soils of Iran. Journal of Plant Nutrition 27: 1149-1162.

Eryuce N, Yagmur B, Colak S (2004) Effect of potassium fertilization on yield, quality and the mineral composition of leaves of apricot (Prunus armenica L.) IPI regional workshop on potassium and fertigation development in West Asia and North Africa, Rabat, Morocco, 2428.

Gill PPS, Ganaie MY, Dhillon WS, Singh P (2012) Effect of foliar sprays of potassium on fruit size and quality of Pathernakh pear. Indian Journal of Horticulture, 69: 512-516.

Hamza A, Bamouh A, Guilli, ME, Bouabid R (2012) Response of Clementine citrus var. Cadoux to foliar potassium fertilization; Effects on fruit production and quality. International potash Institute 8-15.

Hassani G, Rezaei R (2007) Effect of training system and rate of pruning on yield and quality of peach fruit. Agriculture Science Tabriz, 17: 31-38.

Hudina M, Stamper F (2002) Effect of $\mathrm{P}_{2} \mathrm{O}_{5}$ and $\mathrm{K}_{2} \mathrm{O}$ foliar fertilization on fruit quality of pear. Acta Horticulturae, 594: 497-493.
Hudina M, Stamper F, Tagliarini M, Toselli MM, Bertschinger $\mathrm{L}$, Thalheimer $\mathrm{M}$ (2002) Effect of phosphorous and potassium foliar fertilization on quality of pears. Proceedings of the International Symposium on foliar nutrition of perennial fruit plants, Meran, Italy, Acta Horticulturae, 594: 487-493.

Jackson M L (1967) Soil chemical analysis. Asia Publishing House, Bombay, Maharashtra, India.

Janick J (2003) English title: History of Asian Horticultural Technology. Acta Horticulturae, 620:19-32.

Kaith NS, Sharma U, Sharma DD, Mehta DK (2011) Effect of different pruning intensities on growth, yield and leaf nutrients status of Starking delicious apple in hilly region of Himachal Pradesh. Journal of Farm Sciences, 1: 3742.

Kassem HA, El-Kobbia AM, Marzouk HA, ElSebaiey MM (2010) Effect of foliar sprays on fruit retention, quality and yield of Costata persimmon trees. Journal of Food and Agriculture Sciences, 22: 259-274.

Kaur AP, Singh H, Jawandha SK (2012) Effect of pre-harvest application on nutrients and growth regulator on fruit quality of sub-tropical peach. Asian Journal of Horticulture, 7: 565-568.

Krauss A, Jiyun J (2000) Strategies for improving balanced fertilization. International Potash Institute, Basel, Switzerland.

Kumar J, Thakur D (2012) Effect of different pruning intensities on growth, yield, fruit quality and leaf macronutrient content of plum cv. Santa Rosa. The Asian Journal of Horticulture Sciences, 7: 484-487.

Kumar M, Rawat V, Rawat JMS, Tomar YK (2010) Effect of pruning intensity on peach yield and fruit quality. Scientia Horticulture, 125: 218-221.

Lester GE, Jifon JL, Donald JM (2010) Impact of potassium nutrition on food quality of fruits and vegetables: A condensed and concise review of literature. Better crops, 
94: 18-21.

Mahajan BVC, Dhillon BS (2002) Effect of pruning intensities on the fruit size, yield and quality of peach cv. Shan-i-Punjab. Agriculture Science Digest, 22: 281-282.

Neilsen GH, Neilsen D (2011) Consequences of potassium, magnesium sulphate fertilization of high density Fuji apple orchards. Canadian Journal of Soil Sciences, 91: 1013-1027.

Pant P, Nautiyal MC, Singh PC (2015). Effect of different pruning levels on fruit yield and quality of promising peach [Prunus persica (L)Batsch] cultivars. Progressive Horticulture, 47: 66-69.

Papp J (2000) Effect of nitrogen dressings to Jonathan apple trees in a long term experiment. International Journal of Horticultural Sciences, 6: 128-130.

Rai L, Grover D (2006) Manual on Designing and Analysis of Agricultural data. Chaudhary Charan Singh Haryana Agricultural University, Hisar, Pp. 112138.

Rashid A, Kirmani NA, Nazir N, Shafi S (2008) Quality of apple cv. Red Delicious as influenced by potassium. An Asian Journal of Soil Science 13: 227-229.

Sharma DP, Chauhan JS (2003) Response of Prunnig Intensities And Fertilizer Treatments On Yield, Fruit Quality And Photosynthetic Efficiency Of Peach. Acta Horticulture, 662: 237-241.

Sheoran OP (2004) Statistical package for agricultural research workers. Chaudhary Charan Singh Haryana Agricultural University, Hisar.
Singh A, Deka BC, Patel RK, Nath A, Mulieh SR (2012) Effect of pruning time, severity and tree aspects on harvesting period and fruit quality of low chilling peach (Prunus persica). Indian Journal of Agricultural Sciences 82: 862-866.

Thakur A, Arora NK, Sidhu AS, Brar JS (2008) Effect Of Potassium Sprays On the Quality Of Perlette Grapes. Acta Horticulturae, 785.

Thakur K K (2012) Effect of rejuvenation pruning and nitrogen levels on growth, yield and quality of apricot (Prunus armeniaca L.) cv. New Castle. M.Sc. Thesis. Dr. Y.S. Parmar University.

Thakur N, Rana VS (2012) Effect of different pruning intensities on the growth, flowering, yield and quality of nectarines. Indian Journal of Horticulture 69: 117-120.

Thakur N, Rana VS (2014) Influence of pruning intensity on yield and quality of nectarine peach. Journal of Horticulture Sciences 9: 23-26.

Tiwari JP, Mishra NK, Mishra DS, Bisen B, Singh YP, Rai R (2004) Nutrient requirements for subtropical peaches and pear for Uttaranchal; An Overview. Acta Horticulturae 662: 199-204.

Verma MK, Awasthi OP, Giri RK (2010) Prospectus of temperate fruit production in subtropical climate. Presented in National Seminar on "Precision Farming in Horticulture". Pp.28-29.

Volker R, Kirkby EA (2010) Research on potassium in agriculture: needs and prospects. Plant and Soil, 335: 155-180.

\section{How to cite this article:}

Lochan Kaushik, Devi Singh, Ritu Mittal, Ashish Gupta, Gaurav Kant, Shashank Singh and Prashant Kaushik. 2020. Effect of Pruning Intensity and Potash Spray on Biochemical Composition of Peach. Int.J.Curr.Microbiol.App.Sci. 9(11): 2468-2480.

doi: https://doi.org/10.20546/ijcmas.2020.911.298 